\title{
Ethnographic Research on the Music and Dance Tradition of Ikarian Island - A Timeless Evolution - A Dancing Approach of the "Ikariotikos Dance"
}

\section{Lykesas Georgios}

\author{
Department of Physical Education and Sport Science, Aristotle University of Thessaloniki, Greece
}

\author{
Doi:10.5901/mjss.2016.v7n2s1p11
}

\begin{abstract}
The "Ikariotikos dance" has a special place in the music and dance tradition of Ikaria. What is impressive is how intense and timeless is the presence of the tradition of the dance "lkariotikos", not only with its characteristic melody, but also with its multiple and interesting variations. The purpose of this study was to present the traditional musical and dance of Ikaria and more particularly of dance "Sympethera" as far as it concerns its timeless evolution, and its connection with other variations of the dance "Ikariotikos". The presentation and elaboration of the data were based on the synthetic method. Results have shown that, the different conditions and the general musical and dance influences that have been formed in the passage of time, have decisively contributed to the evolution and the formation of the musical and the dance perception of the dance "Ikariotikos".
\end{abstract}

Keywords: Ikaria, Ikariotikos dance, music and dance tradition.

\section{Introduction}

The present study focuses its interest primarily on the detailed analysis of the dancing form and the way that the essential ingredients are classified in the "Ikariotikos dance". Furthermore, it focuses on approaching retrospectively all the confessions and bibliographic references that have drown up the music and dance tradition of Ikaria and more particularly the music and dance tradition of the "Ikariotikos dance".

Ikaria is one of the largest islands in the eastern Aegean. It belongs to the group of Eastern Sporades. It belongs to Samos prefecture along with the islands of Samos and Fourni Korseon. The island took its name from the mythical hero Icarus who according to mythology drowned in southern sea of Ikaria (Themelis, 2001).

It is interesting that we learn the reasons why this particular dance has been preserved and developed in the passage of time, reaching our days, where festivals are still alive and necessary for the island's population. According to Themelis' opinion, dance or -more correctly- the need for dancing that is connected with the temperament of an Ikarian individual is the primary element, the driving force that drifts the equivalent musical creation and action. Considered as the energy and the motion with duration the dance, - if any one takes into consideration that the "lkariotikos dance" is danced in wedding occasions and festivals ceaselessly-"trinoktumcontinuum", as Karas is also characteristically mentioning, in other words in three days and nights ceaselessly -, offers the musician the stimulus and the opportunity to improvise, by forming diverse melodic figures, proportionate to the technical capabilities of the instrument that he plays (ex. Lyre or violin) and considering also his talent, by adjusting them to the frantic -in many cases- vortex of the dancing rhythm. There was definitely a kind of reciprocity as well (Themelis, 2003, 2011). And, this is the "Ikariotikos dance" so far. Dancers have the possibility to be expressed in a special and distinctive way through that kind of dance. The pulse continues to be strong and as a result, that stirs the participants up, by adding a distinct color and provoking a special feeling to them (Pittaka, 2005). Apart from the "Ikariotikos dance", the Ikarians dance, dance tunes in a bilateral rhythm (2/4) and in a kinetic pattern "in 3 steps" way, european dances (valse, tango, foxagleand polka), "island sirtos" from islands and "Balos" and , moreover, "karsilamades" and "Zeimpekika" from Asia Minor.

In the music and dance tradition of Ikaria, an interesting variation and a melodic structure of the "Ikariotikos dance", called "Sympethera" or, in other words, "Palios (Old) Ikariotikos", are integrated. This is, perhaps, the only singing variation of the "Ikariotikos dance", which is still preserved and that is connected with the text that expresses the fatal ending of life and urge for entertainment and dance. The melody of the song is in duple rhythm, just as the other variations of "Ikariotikos dance", and belongs to the type of the "Island syrtos" dance (Themelis, 2001). 


\section{Confessions and Bibliographic References to the "Ikariotikos Dance"}

The first part of the study tries to retrospectively approach all these confessions and bibliographic references that have drown up the music and dance tradition of Ikaria and more particularly the music and dance tradition of the "Ikariotikos dance".

Poulianos offers the very first confessions about the music and dance tradition of Ikaria. His references mostly approach the tradition of Ikaria, by making a simple report with a more literary mood, something that emerges from his works and more particularly from a) "The folk songs of Ikaria", where general remarks for the "Ikariotikos dance" are made and b) In "Ikaria's Folklore, of the Land and Sea", where, among other things, points out that: "... the Ikarian people are a pulsating reality. In all the events, in customs, in social behavior, in thought and in reflection, but first of all through the speech, we find the eternal survival of the Greek race" (Poulianos,1964, 1976).

As far as the music and dance tradition of Ikaria is concerned, the first recordings were made by Karas on a disc vinyl with the title "Songs of Ikaria and Samos". As for the songs and dances of Ikaria, among other things, he states that "genuine and old songs are rare and they are not being sung anymore - since the old way of traditional life has been ceased - wedding songs, songs for Carnival, Easter songs, songs for diverse kinds of feasts and gatherings, poetic tradition or "ribes" ... Nevertheless, the local "Ikariotikos dance" flourishes either by "kneeling or bouncing or shaking..." (Karas, 1991).

The one, though, that dealt more closely at the level of research, with a series of presentations in conferences but also in publications and recordings, regarding the music and dance tradition of Ikaria, was the eminent musicologist and today's professor emeritus Themelis. He is not only originally from Ikaria, but also has a rich living experience of the music and dance tradition of the island, which he experienced as a young lyre player. For example, some of the announcements and publications such as the "Ikarian dance" and "Ikarian Lyra", but especially in his work, the "Fatal trip to Ikaria and the Home-coming" a more extensive reference to cultural, and music and dance events of Ikaria is being made. Also, within the scope of a research project, as a project leader he was, he conducted research on the songs of Ikaria, with the support of the president of "Panikariakis Brotherhood" Philip Mavrogiorgos, something that later contributed to the adoption of a CD called "Songs of Ikaria" (Themelis, 2001, 2003, 2011, 2012). His references to the "Ikariotiokos dance" show how intense and timeless the presence of "Ikariotikos dance" is with its characteristic melody, not only in the musical tradition of Ikaria, but also in the lives of Ikarian people.

Among other things, he states that "... the "Ikariotikos dance" is the identity of the Ikarian people, which reflects in with a direct way the temperament not only of people that experience and recreate it, but also of the itself, the (N)ikaria", and moreover, "... an Ikarian wherever he is, he has the need to dance the "Ikariotikos dance", (Photo 1). This is what someone meets in "Kariotika" celebrations, festivals and other kinds of events, even they are outside lkaria "and he continues" ... the musician with his way of playing passes himself and from his part the mood for dancing to the dancers , leading them sometimes to dance elations, -I would say-exaggerations" (Themelis, 2003, 2011). An interesting description is being made by Mikis Theodorakis in his autobiography, where, among other things, he writes: "... dance leaded them to other dimensions. I would say hieratical ones. It was a bacchanal feast, in the sense of transcendence. These nights had a serious influence on me. "In terms of music" and "in terms of dance" (Theodorakis, 1986 -1995; Themelis, 2003).

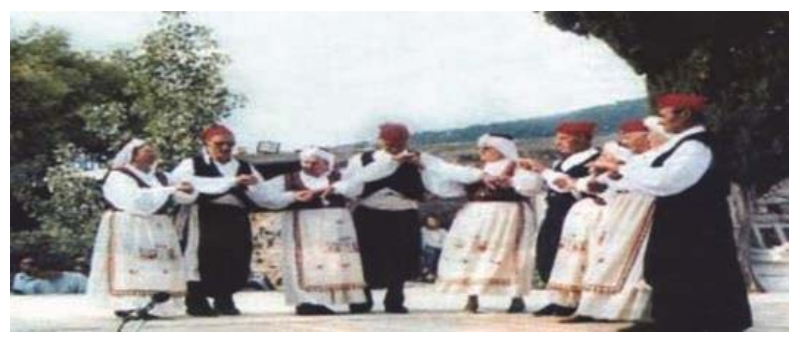

Photo 1: Residents of the Pope area, dancing the traditional "Ikariotikos dance". (Archive Arg. Paschari).

Generally, the instrumentalists that came from the mountain areas of the island had a different temperament and musical sense, than the instrumentalists of the coastal areas. It was the way of playing that reflected in their playing and in the way that improvised, influencing decisively shaping the characteristic physiognomy of the "Ikariotikos dance" of its 
location. It is natural that, these different conditions decisively affect the way that the "Ikariotikos dance" is danced and formed (Themelis, 2003). Special markings on "Music, songs and dances of Ikaria" have been made within the scope of the Musicological conference that had been organized by the "Ikaria Festival", which is edited by Speis (2003). To mention, the eminent professor of Ethnomusicology University Goettingen in Germany Brandl (2003), was one of the speakers that negotiates the structure and the way of playing of "Pano Choros" and Karpathos' dance "Sousta" with Lyra, bagpipe and lute, compared to older recordings of Samuel Baud -Bovy. Moreover, the eminent musicologist and professor emeritus Themelis (2003) approaches the "Ikariotikos dance" and musical tradition of Ikaria, with references from the past and the present reality, by offering his experience and his thoughts, which he experienced as a child. The ethnomusicologist Katsanevaki (2003) examines the structural patterns of the melodic variations of the "Ikariotikos dance", trying to identify any common patterns in other parts of the Aegean too. Likesas (2003) puts up the dance dimension of the "Ikariotikos dance", by making a critical analysis of the bibliographic references, so as to highlight the difficulties of the recordings to the "Ikariotikos dance" study, as it appears through the various outside of Ikaria island researchers. The Lecturer in Musicology Chapsoulas (2003) approaches the musical culture of the Aegean islands during the 18th and 19th century under the prism of literary references and historical sources. The eminent ethnomusicologist Dragoumis mentions the music of Ikaria, as it appears in Greek discography. Musician Patseas (2003) mentions the relation of Lajos Bardos, a music teacher, with the "lkariotikos dance". Speis (2003), through an overall statement, approaches the music of the "Ikariotikos dance", by describing it as a legacy to the cultural heritage of Ikaria (Brandl, 2003; Themelis, 2003; Katsanevaki \& Themelis, 2003; Likesas, 2003; Chapsoulas, 2003; Patseas, 2003; Speis, 2003).

An interesting statement for the "Ikariotikos dance" is being also made within the scope of a bachelor's thesis by Pittaka (2005). It is a comparative study of the musical - tradition of Ikaria and especially of the variations of the "Ikariotikos dance", that also studies their timeless fate and evolution in the passage of time as well. Fradelou refers not only to the characteristics and variations of "Ikariotikos dance", but also to the recommendations of the musicological congress of 2002 (Fradelou, 2008). A Parchari - Koukoulia documents the development of Ikaria's festivals in the passage of time and also the place of "lkariotikos dance" at festivals. Similar approaches are also made by the musicologist M. Mavrogiorgos, with references to the musical and dance variations of "lkariotikos dance", but also by Niouniouskou where, strangely, there are no references to texts of previous researchers of "lkariotikos dance" (Mavrogiorgi, 2008; Niouniouskou, 2008).

\section{Aim of Study}

The purpose of this study was to present the traditional music and dance of Ikaria and particularly the dance of "Sympethera" or "Palios (Old) Ikariotikos and its connection with other variations of the "Ikariotikos dance". Moreover, the significance and importance of the present study relies on the fact for the first time that it tries to highlight the timeless evolution of the above named dance taking into consideration as well the influence of socio-political changes that took place in our country, in general, and especially at the island of Ikaria.

\section{Ethnographical Approach of the "Ikariotikos Dance"}

The Ikarian melody and dance may have received some effects through the passage of time. Initially, "Ikariotikos dance" probably was danced only with the company of a song of which several variations of texts have been survived and then, it was developed both musically and physically. Afterwards, the melody, that was sung, started to be accompanied by the "zygia" (pairs of organs) and mainly by the lyre, and secondly by the "Tsampounofylaka" (Kariotiki bagpipe) and then by violin with the company of a lute or mandolin, in a duple rhythm of course (2/4) (Themelis 2003, 2011). Nowadays, other musical instruments have managed to infiltrate, like the guitar, the bouzouki, the percussion instruments, the accordion, the harmonium ect (Karas, 1991). Primary, dance movements (steps) were more simple, more laminar and smooth, and the grip of the hand was by palms, crossed and low, but also there was a limitation on the improvisation of the first dancer.

This description refers to the dance figure of an old form of "lkariotikos dance", called "Sympethera" or known as "Old Ikariotikos" as well. This dance form of "Sympethera", as well as the song, slowly retreated and instead of it, the form of organic purpose came after. It is common knowledge, of course, that, in general, the dance is more accessible than a song. This actually applies to a large extent for the Ikarian people too. Almost all dances, especially their "Ikariotikos dance" with aptitude and passion, while, those who sing, are very few (Themelis, 2001, 2011).

Dancing, possibly over the years, evolved and became more lively with bouncing, with more kinetic variations and motor combinations, while the dancers were caught by their shoulders. The first dancer that "drags" the dance, was the 
one who improvised from all over the "kavos"(i.e the dance circle). Moreover, the "kavos", (i.e the dance circle), is wide open and all the dancers are passing from the beginning of it. This form of the "Ikariotikos dance", unlike"Sympethera", begins with an introduction of a kinetic pattern" in 3 steps" but always in a duple rhythm (2/4) as well.

Nowadays, the "Kariotikos dance" is danced with some variations from region to region. Certainly, the way of playing and the personality of a traditional musician decisively contributes to the formulation of the special physiognomy of Ikarians purpose (Themelis, 2003, 2011). The most famous variations of the "Ikariotikos dance", that we meet mainly in Ikaria, apart from "Sympethera", are "Tsamourikos" or "Peramaritikos" and "Rachiotikos". In these forms, the sidelining of the first part is also observed and in general, melody has met some changes, leading to the emergence of a newer version of "Ikariotikos dance", known as "Brand new or Newer or New Ikariotikos dance". Among these changes, also belongs the marginalization of the melody of "Tsamourikos" or "Peramaritikos", which neither is being played much anymore - except few instrumentalists - nor is danced, respectively, since the good old dancers have withdrawn.

\section{Connections between the Constituent Elements of Variations of the Ikariotikos Dance}

From a dancing perspective, in all variations of the "Ikariotikos dance", three simple movement combinations are used which are characterized as movements around the area, switching, liftings and stops, which come from combinations of the one "standing indicator" (right or left leg), or repetitions of the same "standing indicator", or changes from the one "indicator" to the other. The dances are developing in a circular orbit to the right, where men and women perform the same movements. The movements' extend of the bottom limps is specified from the dancers' sex, the meter's internal subdivision, the amount of volume and the tempo. The tempo is relatively slow to medium. Men and women take their place and are mixed placed, facing the center of the circle. The two sexes' position is equal within the traditional society of Ikaria.

\section{Analyzing Method}

The data presentation and editing (bibliographic review, videos and musical CDs) was based on the synthetic method (Karas, 1991; Economides, 1997; Themelis, 2001; Tsantiris \& Poulis, 2005; Liavas, 2012; Poziou \& Kourousi, 2012). The analysis of the dancing form of the variations of the "Ikariotikos dance" as they appear in Ikaria's different regions will be a) with the schematic presentation of "Sympethera" or "Old Ikariotikos" movements and its variations and b) with the "J. Adshead" analyzing method as for the dance's constituent elements' classification way, so as to understand their kinetic differences (Holden \& Vouras, 1976; Kalamaras, 1993-1994; Hunt, 1996; Adshehad, et al.,1988; Likesas, 2003; Tyrovola, 1992, 2001, 2010, 2013; Koutsouba, 2010). Taking into account every ethnographic fact of the variations of the Ikariotikos dance, the method of analysis of Adshead (1988) was utilized as it refers to the way of classification, analysis and description of the components and parts of the dance and the recognition of the dance form and the relations among the components of the dance with respect to time. In addition, the comparative method was chosen because it is the scientific method by means of which the common and special in all historic events are being studied (Kabitsis \& Charahousou,1990). Through this method the content of "homogeneous" objects, which constitute an order, is classified and estimated. The comparison of "homogeneous" objects is based on the common features which are essential for the given examination. The most simple and important type of relationships revealed by comparison, is the relationship of identity and difference. The comparison of these relations leads to our ability to respond to questions such as if the objects are identical or different and to what extent.

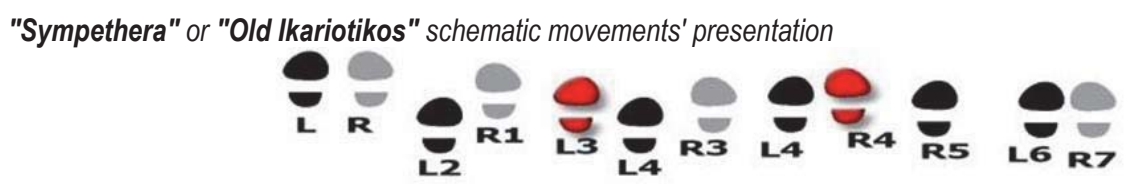

$L=L$ eft foot, $R=$ Right foot, Red Colour $=$ On the air, $1 \ldots 7=$ number of movements (steps) 
"Tsamourikos" or "Peramaritikos", "Rachiotikos" and "New or newer Ikariotikos"schematic presentation of variations' movements

Part A

Part B
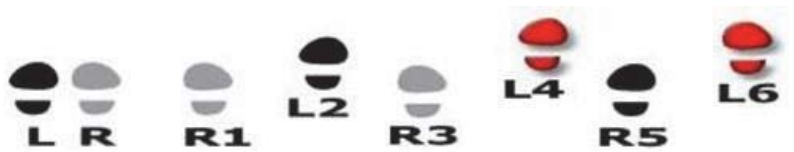

\section{Part B}

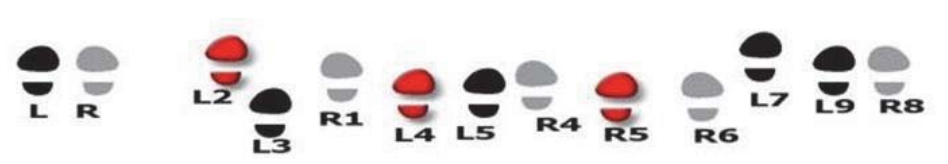

$L=L$ eft foot, $R=$ Right foot, $R$ ed Colour $=$ On the air, $1 . . .7=$ number of movements (steps)

\section{Description and Classification Way of the Dance's Constituent Elements}

"Sympethera" or "Old Ikariotikos": Dance's constituent elements

\begin{tabular}{|l|l|}
\hline Movement & $\begin{array}{l}\text { The movement of the steps is slow, lighthearted, slightly lively and reserved at the same time. A } \\
\text { coordination of movement of the whole team is observed and at the same time there is a restriction } \\
\text { in the improvisation of the first dancer. }\end{array}$ \\
\hline Space elements (Space) & $\begin{array}{l}\text { The dancing shape is circular, the size of the dancing shape is an open circle with direction to the } \\
\text { right. It is a team dance with many people to participate. }\end{array}$ \\
\hline $\begin{array}{l}\text { Dynamic elements: } \\
\text { Rhythmical shape, } \\
\text { Rhythmical organization }\end{array}$ & $\begin{array}{l}\text { A duple rhythm (1+1). Meter 2/4. The rhythm is medium, slow and stable. The intensity level is } \\
\text { characterized as medium strong. The phenomenon of equability and equal rhythm is observed. The } \\
\text { most used rates of duration are eights and quarters. }\end{array}$ \\
\hline Dancers & $\begin{array}{l}\text { Men and women dance together mixed. Hands are connected with a grip by the palms and crossed } \\
\text { low. }\end{array}$ \\
\hline Acoustic elements & $\begin{array}{l}\text { In old times they were possibly dancing only while singing and later both with instrumental music } \\
\text { and song. }\end{array}$ \\
\hline Choreography & \begin{tabular}{l} 
The basic dancing phrase is continuously repeated. There is a specific choreographic structure. \\
\hline Complexes
\end{tabular} \\
$\begin{array}{l}\text { Full participation of all dancers, coordination of movements of almost all of the body parts. } \\
\text { dance's slow rhythmical light supports in the whole foot and with little opening, alternative and light. The } \\
\text { or "Old lkariotikos", because this is the way it was danced during old times. }\end{array}$ \\
\hline
\end{tabular}

Constituent elements of the dance: "Tsamourikos or Peramaritikos" with the same way also "Rachiotikos" is analysed and "New or Newer lkariotikos" as well

\begin{tabular}{|l|l|}
\hline Movement & $\begin{array}{l}\text { The dance has two parts. In the "New Ikariotikos" we have only part B'. The movement of the steps } \\
\text { is lively and in place, limited in switchings, stops and liftings. They are done very close to each other, } \\
\text { with the whole foot touching the ground. The movement of the first dancer is usually more intense } \\
\text { and he improvises on a high degree by changing the steps of the dance. During the first dancer's } \\
\text { improvisations, the rest participate performing the basic dancing phrase or the simple steps or stay } \\
\text { on stop. }\end{array}$ \\
\hline Space elements (Space) & $\begin{array}{l}\text { The dancing shape is circular, the size of the dancing shape is an open circle with direction of both } \\
\text { parts to the right. It is a team dance with the participation of many people. (In our days the first part } \\
\text { is not danced, especially by the young people). }\end{array}$ \\
\hline $\begin{array}{l}\text { Dynamic elements: } \\
\text { Rhythmical shape, } \\
\text { Rhythmical organization }\end{array}$ & $\begin{array}{l}\text { Duple rhythm (1+1). Meter 2/4. Rhythmical action medium strong and stable. The intensity level is } \\
\text { characterized as strong. The phenomenon of equability and equal rhythm is observed. The most }\end{array}$ \\
\hline used duration rates are eights and quarters. \\
\hline Dancers & Men and women mixed dance together in both parts. Hands connected with grip by the shoulders. \\
\hline Acoustic elements & Instrumental music only (the complexity of the movement possibly does not help the song). \\
\hline Choreography & $\begin{array}{l}\text { Basic dancing phrase continuously repeated in the first and second part. Specific choreographic } \\
\text { structure. }\end{array}$ \\
\hline Complexes & $\begin{array}{l}\text { Full participation of all dancers, mainly of the first ones, movements' coordination of almost all body } \\
\text { parts. Movements with light supports in the whole foot and with little opening, alternate and light. } \\
\text { Movement on place and the improvisation's variety from the first dancer are typical. }\end{array}$ \\
\hline
\end{tabular}




\section{Connections between the lkariotikos Dance's Variations' Constituent Elements Regarding the Time}

In all Ikariotikos dance's variations we observe that each dancing phrase is structured by three kinetic patterns, each of which corresponds to a musical meter 2/4 (rhythmical pattern). The measurement is according to European musical meter. The intonation is always given to the first time of the duple rhythm and concur, in the first kinetic element, of each kinetic pattern's first part. Consequently, unanimity of dance's emphasis connection and music's intonation is observed, where the powerful point and the dance's movement "position" perfectly match.

All dancing phrases of these variations are structured by similar kinetic elements. The duration of each kinetic pattern is specified by the duration of the corresponding rhythmical, without meaning that in the dance's development process, within time, any particular delays or abbreviations of the individual rhythmical motives are observed. All these variations depend on the moment intentions, both from the dancers and musicians, (Photo 2).

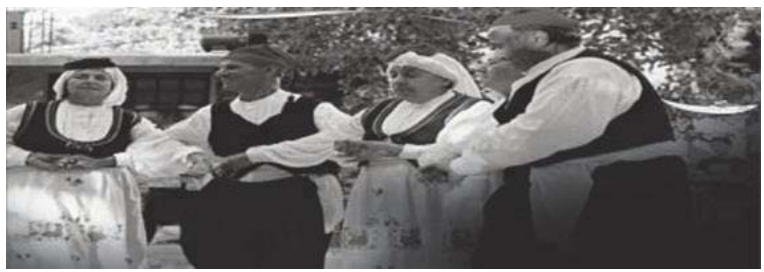

Photo 2: Ikarian people are dancing the "Old" Ikariotikos or "Sympethera".

By observing the "Old Ikariotikos" or "Sympethera", we can find only "one" part, where we have seven movements in total, during which we have two movements to the right where alternately "support indicators" change is observed, with right foot to the right (1), left foot's footing behind the right foot (2), movement of the right foot - position to the right (3) and consequently opposite footing of the left foot to the left (4) and right footing again to the right (5) and in the end, we have a footing of the left foot before the right one (6) and a small movement - position of the right foot next to the left (7) almost in place.

Regarding the "Peramaritikos or Tsamourikos" and "Rachiotikoslkariotikos", we have two parts (A) and (B). In part (A), we have six movements in total during where we have two movements to the right, and alternately "support indicators" right and left change is observed ( 1 \& 2), consequently a movement - position to the right (3) and a lifting in the left foot (4) and in the end a small movement - position of the left foot to the left (5) and lifting in the right foot (6).

In part B, we have nine movements in total during which, the dance starts with a footing in the right foot (1) and a swing in the left (2), which starts sideways and to the back of the right with eventually a footing in the left to the right (3), consequently a footing of the right foot to the right (4), an opposite footing in the left to the left (5) and again right's footing to the right (6) and finally, we have a left foot's footing before (7), a right's footing on the toes next to the left (8) and in the end foo ting of the left, next to the right (9) almost in place. For the "New or Newer Ikariotikos" we have only one part, which is the same to the part b of "Tsamourikos" or "Peramaritikos" or "Rachiotikos Ikariotikos", (Photo 3).

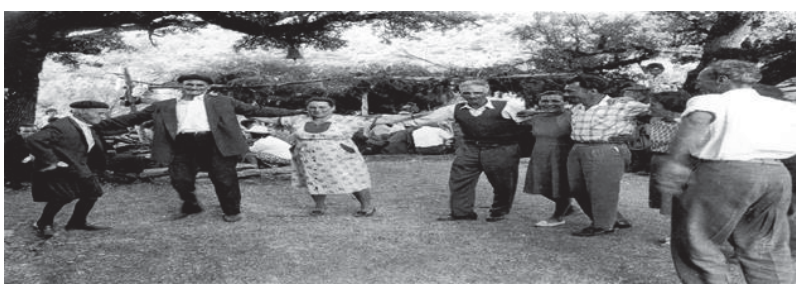

Photo 3: Ikarian people dancing the "Ikariotikos" dance ( Ch. Malachia file, 1968).

\section{Discussion}

The data collected during the bibliographic review of this ethnographic paper about "lkariotikos dance" and its variations, lead us to the following results, all "Ikariotikos dance" forms have a duple rhythm, musical tempo 2/4, rhythmical action 
from medium slow to relatively fast and stable and the volume level medium strong. The "Old Ikariotikos" form presents one part only at past times it was danced possibly with song only, later with instrumental music and song and gradually started to decay, stopped to be sang and eventually was put aside.

The people of the old generation as carriers of live musical dancing tradition stopped existing, sealing this era, where the lifestyle was closely connected to customs, traditional songs and their dances (Themelis, 2003). Many customs and popular events connected to dancing and singing were not able to survive, because they have lost not only their magical religious character, but their social feasibility as well (Dimas, 2010). For the rest, Ikariotikos dance's variations the part (A) is the same. As far as part (B) of all other variations of the "lkariotikos" dance is concerned, it was observed that:

"Tsamourikos or Pemaritikos" has small movements, sharp and twisted, in the place with direction to the right. This form was mainly danced from the older people representing slowly a declining course to destinction (the dance of the elderly "kounistos"). "Rachiotikos" was danced more from the new generation with more dynamic movements, the last years however, part (A) is not performed any more. Today, we meet a new form which is called "New Ikariotikos", (Photo 4). It is an evolution and combining of all forms, analyzed before, without having any difference and it is danced especially from the new generations. (Fradelou, 2008; Pitakka, 2005). Pasxari-Koukoulia "...from the dancers of the modern fests the older people, which used to be the first to dance, are absent. The manliness way of dancing and the dance figures "tsalimia" of dance Ikariotikos were replaced by the cheers of people in the rhythm of the modern melodied of Ikariotikos..." (Pasxari-Koukoulia, 2011).

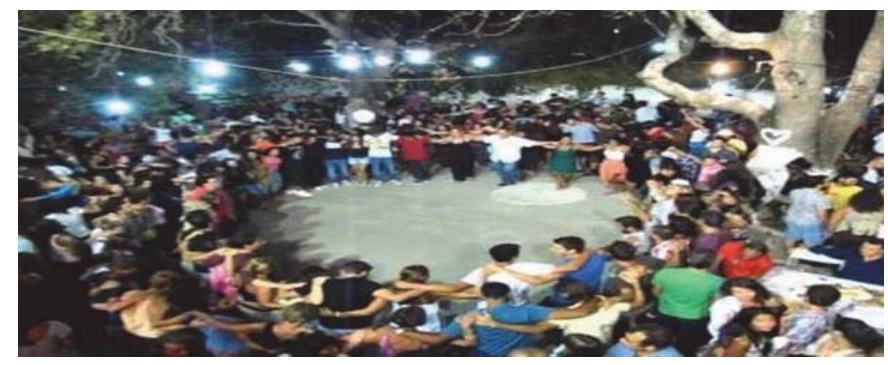

Photo 4: Participants in the fest of Agioi Anargiri in Karavostamo village, Ikaria (2012).

The different conditions that were formed over the years and overall musical influences, contributed to the change in both temperament and musical perception of residents and musicians.

So the music of "Ikariotikos" not only differed from region to region of Ikaria, but in the way every musician played it in many cases in the same area. Naturally, they influenced decisively the way that the dance "Ikariotikos" is danced and formed (Themelis, 2003, 2011).

Apparently, this simple singing form of the "Old Ikariotikos" or "Sympethera", is perhaps the primary form of "Ikariotikos dance". This was probable formed and evolved, through the passage of time and due to the various influences, to the instrumental variations that are the dominant forms nowadays, and are defining the special dancing form of "lkariotikos dance" in the various places of Ikaria.

But we cannot yet evaluate the effects that the globalization will have in the future which occurs nowadays in a really rapid way, penetrating in the most remote places on earth, creating new life conditions which are effecting every walk of it.

However, the need for maintenance and cultivation of music and dance of our tradition has been acknowledged, even in some case some attempts are being done to revive, although that renewed musical tradition naturally has its own new character, which is in many cases characterized by sophistication (Themelis, 2003, 2011). In recent years there is an effort from cultural institutions of Ikaria, to reintegrate all forms of the Ikarian dance and especially "Sympethera" and its songs, in the island's music and dance tradition.

\section{Conclusions}

During the present research some concerns have emerged regarding the primary dance physiognomy of the "Ikariariotikos dance", especially that of "Sympethera", such as: a) how the form of the "Old Ikarian dance" was lost and at 
the same time the song accompanying dance was put aside; b) how the "lkariotikos dance" dominated as an instrumental dance; c) why are they no longer singing in Ikaria, as it is happening in other traditional symbiotic societies; and d) finally how the figural-dance variations of Ikariotikos dance emerged from place to place.

Taken into consideration all the above evidence, we may conclude that there is a timeless development and a continuous change of the Ikarian dance and the musical tradition of Ikaria. This may be attributed due to the changing economic and social conditions, which, in turn, led to the cultural deterioration of lifestyle and the different way of entertainment (from the festivals and the rites of passage, to the nightclubs, cafes and bars). Moreover, the interruption of the bonds and the moral values of the past, contributed, also, substantially to the deviation of the normal evolution of the traditional culture, promoting the foreign and the modern, i.e. change and marginalization of the functionality of dance and song, removal of the traditional musical instruments in a more modern and richer timbres (from the lyre and tsampounofylaka the violin, the lute, the guitar, harmonium and sometimes and various percussion). However, the Ikarian dance and the musical tradition of Ikaria, seems to be a continuous challenge for the future presumptive researcher.

\section{References}

Adshead, J., Hodgens, P., Briginshaw, V. \& Huxley, M. (1988). Dance analysis: Theory and practice. London: Dance Books. Greek Editor: Tirovola, V. \& Koutsoumpa, M. (2007). PX Pasxalidis publications. Athens.

Brandl, R. (2003). Structure and Practice in playing "Pano Dance" and "Sousta" in Karpathos with bagpipe-Lyre - Lute. In "Music, songs and dances of Ikaria" records of the Musicological Congress, Ikaria, 2002 Curator: Th. Speis, publisher: Papagrigoriou-Nakas, Athens, p. 64-81.

Chapsoulas, A. (2003). The Musical Culture of the Aegean Islands in the Period of the 18th and 19th Century. In "The Music, songs and dances of Ikaria" records of the Musicological Congress, Ikaria, 2002 Curator: Th. Speis, publisher: Papagrigoriou-Nakas, Athens, p.82 - 99.

Dimas, I. (2010). Society and Greek Traditional Dance, and teaching of Greek traditional dances. In I. Dimas V. Tyrovola, \& M. Koutsouba, Greek Traditional Dance: consideration of speech, writing and its teaching, (Editors are the writers),Athens,p.17-64.

Dragoumis, M. (2003).Music of Ikaria in Greek discography.In "The Music, songs and dances of Ikaria" records of the Musicological Congress, Ikaria, 2002 Curator: Th. Speis, publisher: Papagrigoriou-Nakas, Athens, p. $100-106$.

Fradelou, Chr. (2008). Ikariotikos - Dancing part. Online magazine: Nikaria (www.nikaria.gr) Issue 7, p. 25.

Holden, R. \& Vouras, M. (1976). Greek Folk Dances. Folkraft-Europe. Brussels, Belgium.

Hunt, Y. (1996). Traditional Dance in Greek Culture. Centre for Asia Minor Studies, Musik Folklore Archive. Athens.

Kabitsis, Ch. \& Charahousou-Kabitsi, Y. (1990) Research methods in sport. Salto. Thessaloniki.

Kalamaras G. (1993-4). Dances and traditional elements of Ikaria, Notes for the course of Greek Traditional dances of Physical Education in Komotini. Komotini.

Karras, S. (1991). Songs of Ikaria and Samos, publishing disc of the Association for the Dissemination of National Music (SDNM 128), Greek Echoes 2. Athens.

Katsanevaki, A. \& Themelis, D. (2003). Structural Patterns on Melodic Variations of Ikarian Dances. In "The Music, songs and dances of Ikaria" records of the Musicological Congress, Ikaria, 2002 Curator: Th. Speis, publisher: Papagrigoriou-Nakas, Athens, p. 22 49.

Liavas, L. (2012). The Earths salt. Ikarias' feast. Responsible production ERT .: Athens.

Likesas, C. (2003). The Ikariotikos dance outside of the island of Ikaria. In "The Music, songs and dances of Ikaria" records of the Musicological Congress, Ikaria, 2002 Curator: Th. Speis, publisher: Papagrigoriou-Nakas, Athens, p. 50 - 63.

Mavrogeorgi, M. (2008). The Ikariotikos dance. Online magazine: Nikaria (www.nikaria.gr), Issue 7, pp. 20.

Niouniouskou, B. (2008). Dos'tou ,dos'tou pera dos'tou foustaniou sou aera...Online magazine: Nikaria (www.nikaria.gr), Issue 7, p. 21.

Economides, N. (1997). East of the Aegean. Music CD 101. Old Ikariotikos melody. Production: VERSO.

Parcharia- Koukoulia, A. (2011). Festivals of Ikaria. Journal: Company Ikarian Studies. Athens, p. 16-17:16.

Patseas, M. (2003). The Ikariotikos Dance and Lajos Bardos. In "The Music, songs and dances of Ikaria" records of the Musicological Congress, Ikaria, 2002 Curator: Th. Speis, publisher: Papagrigoriou-Nakas, Athens, p. 107 - 125.

Pittaka, M. (2005). Ikariotikos dance. Graduation Thesis, Department of Physical Education, Athens.

Poziou, P. \& Kourousi, N. (2012). Ikarian, Chorostalismata. Music CD. Production: Panikarios Association "Artemis Tauropolos". Athens.

Poulianou, A. (1964). Folk songs of Ikaria, Athens.

Poulianou, A. (1976). Folklore of Ikaria. Of the Land and Sea. Volume A. Athens.

Speis, Th. (2003) .The Music of the lkarian dance- our cultural heritage. In "The Music, songs and dances of Ikaria" records of the Musicological Congress, Ikaria, 2002 Curator: Th. Speis, publisher: Papagrigoriou-Nakas, Athens, p. 8 - 10.

Themelis, D. (2001). Songs of Ikaria. Greek Traditional Music 2. CD publication of the Music Department, AUTH Research Committee, Thessaloniki.

Themelis, D. (2003). "Ikariotikos dance - Tradition and current reality- experiences and thoughts." In "The Music, songs and dances of Ikaria" records of the Musicological Congress, Ikaria, 2002 Curator: Th. Speis, publisher: Papagrigoriou-Nakas, Athens, p. 11-21.

Themelis, D. (2011). Ikarian Lyra and Ikariotikos. Journal: Company Of Ikarian Studies, Athens, p. 11-15:16.

Themelis, D. (2012). Fatal trip to Ikaria and turning back. (Publisher is the author). Thessaloniki. 
Theodorakis, M. (1986 to 1995). The Roads of Archangel, Kedros, Volume II, Athens.

Tsantiris, L. \& Poulis, L. (2005). The Ikarians are dancing. Music CD.

Tyrovola, V. (1992). Greek Traditional Dancing Rhythms. ed. Gutenberg, Athens.

Tyrovola, V. (2001). The Greek dancing. A different approach. Gutenberg. Athens.

Tyrovola, B. (2010). Art and aesthetics: the aesthetics and the art of dance. At The. Dimas, B.

Tyrovola, M. Koutsouba, Greek Traditional Dance: Consideration for Spech, writing and its teachings. (Editors are the writers). Athens. Tyrovola, B. (2013). Dance Issues A \& B About dance ... (Publisher is the author). Athens. 